\title{
Nurses' Self-report on the Infection Control Unit Activities and their Experience in the Hospital toward Nosocomial Infections in the Sulaimani Hospitals
}

Ramand Muhammad Haji; Department of Community Health, Technical College of Health, Sulaimani Polytechnic University, Sulaimani, Iraq. (Correspondence: ramandranya@yahoo.com)

Dana Abdilmagid Abdilkarim; Department of Medical Laboratory, Technical College of Health, Sulaimani Polytechnic University, Sulaimani, Iraq.

Salar Ibrahim Ali; Department of Community Health, Technical College of Health, Sulaimani Polytechnic University, Sulaimani, Iraq.

Srwa Salih Mohammad; Department of Community Health, Technical College of Health, Sulaimani Polytechnic University, Sulaimani, Iraq.

\section{ABSTRACT}

Background and objectives: Nurses can prevent the occurrence and transmission of nosocomial infections by following infection control measures such as wearing gloves and masks, using appropriate disinfection of skin and preventing accidental needle-stick injuries. This research aimed to evaluate the availability of hospital uniforms, personal protective equipment, and infection control activities at hospitals in Sulaimani in the Kurdistan Region of Iraq, and to examine nurses' experience of nosocomial infections.

Methods and materials: A cross-sectional study was performed at 10 governmental hospitals during the period from 20th February to 28th September 2018. 525 nurses were selected as participants by a convenience sampling method. A self-administrated questionnaire was used to collect data, which were analysed using SPSS software.

Results: The results showed that 268 nurses (51\%) reported that their hospitals provided sufficient uniforms to all the medical staff and the majority of nurses, 444 respondents $(84.6 \%)$ stated that they were responsible for cleaning their working uniforms. 441 nurses reported that they did not acquire a nosocomial infection, and 479 (91.2\%) did not have an accident during their work in the hospital. $79.9 \%$ of the nurses (404) reported recapping syringe needles after the usage, and $98(18.7 \%)$ gave a low rating to the infection control unit activity in their hospitals. Finally, more than half of nurses (330) representing $62.9 \%$ of the sample were vaccinated against nosocomial infections.

Conclusions: Most of Sulaimani governmental hospitals are providing sufficient uniforms for the health staff, the majority of nurses were vaccinated against one or more nosocomial infections, and the majority of nurses do needle syringe recapping.

Keywords: Nosocomial infection, Infection control unit, Nurse's accident.

Received: 17/03/2020

Accepted: $27 / 7 / 2020$

Published: 30/11/2020

\section{INTRODUCTION}

Nosocomial infections (NIs) are present in both developed and developing countries, but $75 \%$ of this burden occurs in developing countries [1]. The number of NIs in lowincome countries is three times higher than in high-income countries and the neonatal incidence is 3-20 times higher [2].
According to Samuel and Alp, this difference in developing countries is related to the ineffective infection control programmes resulting from lack of problem awareness, understaffing, heavy workload, overcrowding, erratic electricity supply, poor water supply, ineffective 
antibiotic policies with the emergence of multiple antibiotic-resistant microbes, poor laboratory backup, poor funding, lack of personal protective equipment, and unsafe working practices $[3,4]$. NIs have serious negative consequences such as increased costs of healthcare, prolonged hospital stay, economic hardship to patients and their families, long-term disability, increase mortality rate and increase of antimicrobial resistance [5-8]. NIs are caused by everpresent pathogens that are present in the air, on surfaces and equipment such as bacteria, viruses and fungi [9]. Furthermore, nosocomial cases do not include only patients but also healthcare workers, visitors and suppliers who got the infection during work in a hospital environment [10, 11].Nurses are vital healthcare workers who are in more continuous and direct contact with patients than other health staff. They are therefore at higher risk of NIs and also play a vital role in their transmission [12]. Research studies show that nurses have a big effect on transfer of NIs $[9,13,14]$. Furthermore, NIs are an occupational hazard for nurses [15] and including this topic in a nursing curriculum has a significant role in their prevention [16]. Infection prevention and control measures aim to protect patients and hospital staff from acquiring an infection while they are inside the hospital [17]. Infection control should be one of the main responsibilities of all hospital workers and they should have appropriate knowledge and essential related skills [18]. Nurses can prevent the occurrence of NIs by following control measures such as putting on gloves and masks, using appropriate disinfection of skin, changing the infusion sets, avoiding contact with secretions, applying standard precaution principles, appropriate isolation of patients and preventing accidental needling [19]. This study aimed to evaluate the availability of hospital uniforms, personal protective equipment and infection control activities in Sulaimani hospitals and to investigate the nurses' experiences of nosocomial infections

\section{METHODS}

A cross-sectional study was carried at governmental hospitals in Sulaimani in the Kurdistan Region of Iraq (Table 1). The study included 887 nurses and excluded nurses who were on vacation during the period of study and who worked in positions without direct contact with patients. Data were collected from 20th February to 28th September 2018. To determine the study sample size, Daniel's method with the formula $(\mathrm{N}=(\mathrm{Z}) 2 * \mathrm{P} *(100-\mathrm{P}) / \mathrm{D} 2)$ was used [20]. The prevalence rate $(P)$ assumed was $45 \%$ depending on Kaushal's study in 2015 [21], confidence level Zalpha (Z) 1,96, confidence interval difference (D) 4.5 at $10 \%$ of the prevalence and power of prevalence was $45 \%$ decreased to $39 \%$ to cover the missing data. After applying this formula, the sample size of the study was approximately 525 nurses. A convenience sampling method was used to select the participating nurses. The sample size was divided for each of the 10 hospitals by a proportion formula, which is as follows: (number of nurses in a group / total number of nurses *sample size). The sample size number for each hospital is shown in Table 1.A self-administrated questionnaire was utilised to collect data and the firs section included questions about demographical information and workplace characteristics such as age, gender, professional education, work experience, hospital, department etc. (Table 1). The second section contained multiplechoice questions about Personal Protective Equipment (PPE) provided by hospitals. The third section included questions about nosocomial infections-related subjects studied at the university, Nls training in 
the hospital, nurses'awareness of infection control unit, their estimate of the safety of their hospital, experiences of accidents and acquired NIs, and recommendation to their hospital regarding $\mathrm{NI}$ control. The validity of the questionnaire was confirmed through review by infection control experts at the Sulaimani hospitals and Sulaimni Polytechnic University. After the collection, the data were analysed using SPSS (Statistical Package for the Social Sciences) version 22.To obtain descriptive statistics, the mean, standard deviation, frequency and percentage were calculated. In addition, the Endnote software version 7.5 was used for management of the references.
This study was approved by the Sulaimani Directorate of Health and the administrations of the involved hospitals. Furthermore, the researchers obtained the verbal informed consent from nurses after explaining the details and importance of the study.

\section{RESULTS}

This study included 525 nurses at 10 general hospitals in Sulaimani (Table 1). The mean \pm standard deviation (SD) of nurses' age were $33.28 \pm 8.42$ with a range of $19-62$ years old. Most of the nurses were in the 26-36 years old group (41.5\%), followed by the $37-47$ years old group (27.3\%) and the 25 or less years old group (19.8\%) .

Table 1: Representative number of nurses and selected nurses in each governmental hospitals in Sulaimani

\begin{tabular}{lcc}
\hline Hospital & Number of nurses & Selected nurses \\
\hline Shar General Hospital & 262 & 155 \\
Maternity Teaching Hospital & 105 & 62 \\
Internal Teaching Hospital & 88 & 52 \\
Paediatric Teaching Hospital (Dr.jamal) & 87 & 52 \\
Cardiac Specialists Hospital & 72 & 43 \\
Emergency Surgery Hospital & 70 & 41 \\
Burn and Plastic Emergency Hospital & 69 & 41 \\
Surgery Teaching Hospital & 58 & 34 \\
Internal Emergency Hospital (Hemn) & 40 & 24 \\
Hiwa Hospital for Cancer & 36 & 21 \\
Total & $\mathbf{8 8 7}$ & $\mathbf{5 2 5}$ \\
\hline
\end{tabular}

as demonstrated in Figure 1. The majority of respondents were females (67\%) in comparison to males (33\%). Most of the nurses held institute diploma certificate (66.1\%), followed by a bachelor degree (16.4\%), and a high school diploma degree $(14.5 \%)$.

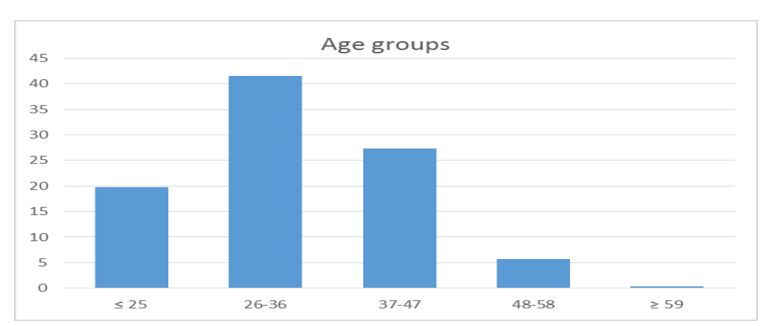

Figure 1. Nurses' age groups
Figure 2 and 3). In terms of place of work, 192 nurses (36.6\%) worked on hospital adult wards, 99 (18.9\%) practised in an emergency room, $78(14.8 \%)$ in the operating theatre, $67(12.8 \%)$ in the ICU, 28 (5.3\%) on the paediatric ward, $11(2.1 \%)$ in the premature babies unit, and 50 (9.5\%) of nurses did not disclose their workplace.

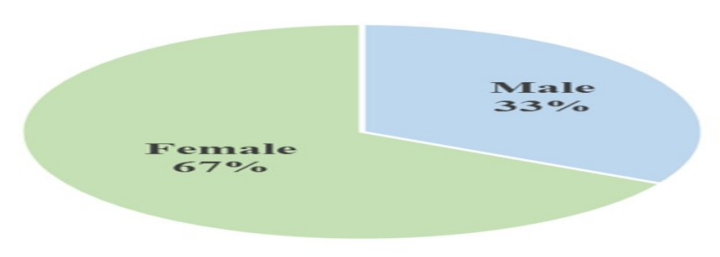

Figure 2. Nurses' gender 


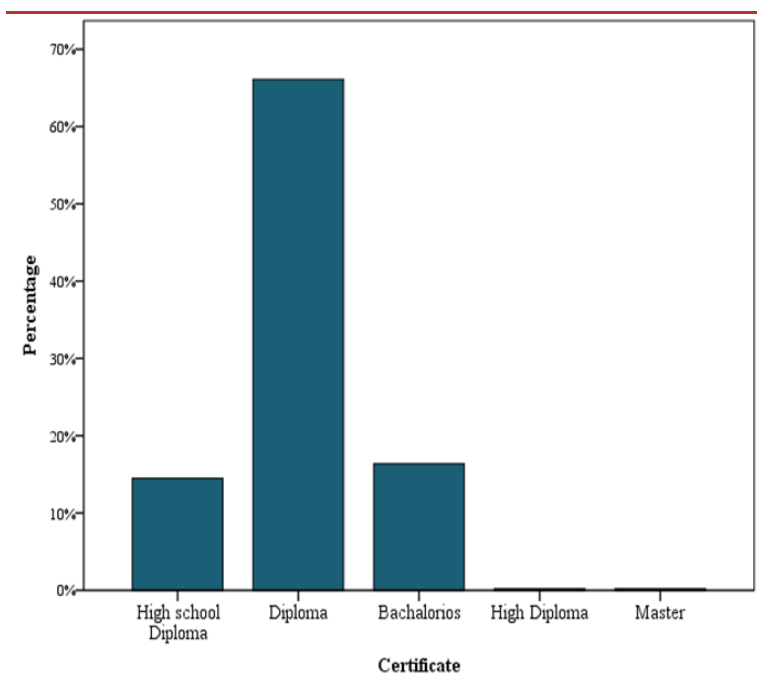

Figure 3. Nurses' professional education

(Table 2).The majority of nurses (295) had 8 or fewer years of experience (56.2\%), 116 nurses worked for 9-17 years (22.1\%), while there was 1 nurse who had 36 years of experience (0.2\%). 14 nurses (2.7\%) did not provide this information. Furthermore, near half of the participated nurses (227/ 43.3\%) had every workday contact with patients, followed by 3-4 days of contact per week (177/33.6\%). 111 (21.2\%) of nurses had less than 3 days of patient contact per week and 10 nurses (1.9\%) did not answer the question (Table 2).The results in Table 3 show that 268 nurses (51\%) reported that hospitals provided sufficient uniforms for staff. However, one-third (194) of the participated nurses (37\%) indicated that the hospitals did not provide uniforms and $58(11 \%)$ of respondents did not have information about whether hospitals provided uniforms and gloves. The inquiry into the experiences of participated nurses with the cleaning of their working uniforms at hospitals revealed that 444 nurses (84.6\%) stated that they were responsible for washing their working uniforms and 41 $(7.8 \%)$ stated that their working uniforms were cleaned by the hospital cleaning staff (Table 3).Furthermore, a large number of nurses stated that their hospitals did not have a dedicated team for checking and cleaning medical staff uniforms; whereas, 144 (27.4\%) of the participating nurses said that the hospitals had such a team. $86(16.4 \%)$ of participants did not have information to answer this question. $139(26.5 \%)$ of participating nurses gave low and 139 (26.5\%) allocated a very good satisfaction rating for their hospital uniforms followed by a good satisfaction rating by 118 nurses $(22.4 \%)$.

Table 2: Distribution of nurses' workplace characteristics

\begin{tabular}{|c|c|c|c|}
\hline \multicolumn{2}{|c|}{ Variables groups } & \multirow{2}{*}{$\begin{array}{c}\text { Frequency } \\
99\end{array}$} & \multirow{2}{*}{$\begin{array}{l}\text { Percentage } \\
\text { (18.9) }\end{array}$} \\
\hline & Emergency room & & \\
\hline & $\begin{array}{l}\text { Intensive care } \\
\text { unit (ICU) }\end{array}$ & 67 & (12.8) \\
\hline \multirow{8}{*}{$\begin{array}{l}\text { Hospital } \\
\text { working } \\
\text { units }\end{array}$} & Paediatric wards & 28 & (5.3) \\
\hline & Premature unit & 11 & (2.1) \\
\hline & Surgery room & 78 & (14.8) \\
\hline & Adult wards & 192 & (36.6) \\
\hline & Total & 475 & $(90.5)$ \\
\hline & Missing & 50 & (9.5) \\
\hline & $\leq 8$ & 295 & $(56.2)$ \\
\hline & $9-17$ & 116 & (22.1) \\
\hline \multirow{7}{*}{$\begin{array}{l}\text { Experi- } \\
\text { ence } \\
\text { (year) }\end{array}$} & $18-26$ & 79 & (15) \\
\hline & $27-35$ & 20 & (3.8) \\
\hline & $\geq 36$ & 1 & $(0.2)$ \\
\hline & Total & 511 & (97.3) \\
\hline & Missing & 14 & $(2.7)$ \\
\hline & Always & & \\
\hline & workday & 227 & $(43.3)$ \\
\hline \multirow{4}{*}{$\begin{array}{l}\text { Period } \\
\text { in con- } \\
\text { tact } \\
\text { with the } \\
\text { patients } \\
\text { per } \\
\text { week }\end{array}$} & week ) & & \\
\hline & $\begin{array}{l}\text { Sometimes (3-4 } \\
\text { days per week) }\end{array}$ & 177 & (33.6) \\
\hline & $\begin{array}{l}\text { Few-times (less } \\
\text { than } 3 \text { days per } \\
\text { week ) }\end{array}$ & 111 & (21.2) \\
\hline & Total & 515 & $(98.1)$ \\
\hline & Missing & 10 & (1.9) \\
\hline
\end{tabular}


Table 3 :Distribution of personal protective equipment availability

Variable groups

Does the hospital provide sufficient uniforms for health staff?

\begin{tabular}{lll}
\hline Yes & 268 & $(51)$ \\
No & 194 & $(37)$ \\
Do not know & 58 & $(11)$ \\
Total & 520 & $(1)$ \\
Missing & 5 & $(9)$
\end{tabular}

Who has the responsibility of cleaning your work uniforms in the hospital?

$\begin{array}{lll}\text { Hospital cleaning staff } & 41 & (7.8) \\ \text { Myself } & 444 & (84.6) \\ \text { Others } & 29 & (5.5) \\ \text { Total } & 514 & (97.9) \\ \text { Missing } & 11 & (2.1)\end{array}$

Does the hospital have a special team for checking and cleaning health staff uniforms?

$\begin{array}{ll}\text { Yes } & 144\end{array}$

No

Do not know 86

Total

522

Missing

If yes, how often are the uniforms washed?

Monthly 8

Weekly

Daily 52

Not in regular times

Total

Missing

If you rate your working uniform, what rate do you give it out of $100 \%$ ?

Very low $(\leq 25 \%)$ 
Table 4 reveals that 441 nurses (84\%) reported that they did not acquire any NIs, and 80 nurses (15.2\%) claimed that they acquired infection from working in the hospital. Furthermore, the infection was the most repeated (21 nurses, 34.4\%) occupational health problem compared with allergy and influenza at 20 nurses (32.8\%) for each. The majority of nurses (479) did not have an accident during their duty at the hospital (91.2\%), while 41 respondents (7.8\%) experienced an accident at work. A needle-stick injury was the most common accident suffered by 18 nurses (51.4\%), 16 respondents (45.7\%) accidentally cut themselves with a sharp object, while a spillage of blood was the least common accident (1 case, $2.9 \%$ ). The majority of nurses (404) reported recapping syringe needles after using it on the patients (76.9\%), and 119 (22.7\%) of nurses denied recapping. The results related to nurses' knowledge about an infection control unit in their hospitals showed that 320 nurses (61\%) were aware that their hospital had an infection control unit, 109 (20.7\%) of nurses reported that there was no such a unit in their workplace, and 89 nurses (17\%) did not know. In addition, most (98) of participating nurses (18.7\%) gave a low rating to an infection control unit activity in their hospitals and followed by 80 good ratings (15.2\%), and 68 very good ratings (13\%). The very low rating of the activity of the infection control unit was given by 29 nurses (5.5\%).Nurses' reports on their safety and vaccinations for nosocomial infections. The results in Table 5 indicate that most of the nurses 330 (62.9\%) were vaccinated against $\mathrm{NI}$ and 185 nurses (35.2\%) of nurses did not receive vaccinations. 198 nurses (76.7\%) were vaccinated against the Hepatitis $B$ virus (HBV), followed by 33 nurses who received an Influenza vaccine (12.8\%), Tetanus (TT) 24 nurses (9.3\%) and Tuberculosis (TB) 3 nurses (1.2\%).
Nurses' reports on their safety and vaccinations for nosocomial infections. The results in Table 5 indicate that most of the nurses 330 (62.9\%) were vaccinated against $\mathrm{NI}$ and 185 nurses (35.2\%) of nurses did not receive vaccinations. 198 nurses (76.7\%) were vaccinated against the Hepatitis $B$ virus (HBV), followed by 33 nurses who received an Influenza vaccine (12.8\%), Tetanus (TT) 24 nurses (9.3\%) and Tuberculosis (TB) 3 nurses (1.2\%).Concerning the safety of their working place, the majority (145) of nurses $(27.6 \%)$ gave a low rating to their working place safety, followed by a very good rating by 127 nurses (24.2\%), and 110 good ratings (21\%). 64 nurses (12.2\%) evaluated safety in their hospital as very low. Furthermore, the study investigated the nurses' fear of acquiring occupational NIs during work in the hospital. The majority of nurses (427/81.3\%) stated that they were afraid of getting NIs, while 85 nurses $(16.2 \%)$ of respondents were not afraid. Moreover, this study explored, how nurses maintained hygiene during nursing procedures. Most of the nurses (347), which represents $66.1 \%$ self-reported that their compliance was very good, followed by a good rating by 87 nurses (16.5\%), and low rating by 34 respondents $(6.5 \%)$, while 4 nurses rated their compliance to hygiene as very low (0.8\%).Finally, the majority (397) of nurses (75.6\%) who participated in this study reported that they consider NIs very seriously during their work in the hospital environment and 45 of them (8.6\%) stated that they do not consider $\mathrm{NI}$ seriously. According to the results, 10 nurses (1.9\%) did not care about NIs and 57 respondents (10.9\%) were not sure how to deal with $\mathrm{NI}$ in their working environment. 
Table 4: Distribution of nurses' accidents and nosocomial infections

Variable groups $\quad$ Frequency Percentage

Have you acquired any infection related to your work in the hospital?

\begin{tabular}{lll}
\hline Yes & 80 & $(15.2)$ \\
No & 441 & $(84)$ \\
Total & 521 & $(99.2)$ \\
Missing & 4 & $(0.8)$
\end{tabular}

If yes, what was the type of infection?

$\begin{array}{lll}\text { Allergy } & 20 & 1(32.8 \\ \text { Infection } & 21 & 1(34.4 \\ \text { Influenza } & 20 & (32.8) \\ \text { Not mentioned } & 19 & \end{array}$

Did you have an accident in the hospital that may cause nosocomial infection?

$\begin{array}{lll}\text { Yes } & 41 & (7.8) \\ \text { No } & 479 & (91.2) \\ \text { Total } & 520 & (99) \\ \text { Missing } & 5 & (1)\end{array}$

If yes, what was the type of accident?

Spill blood

$1 \quad(2.9)$

Cut $16 \quad$ (45.7)

Needle-stick injury 18

Not mentioned 6

Do you recap needle syringes after been used on the patients?

$\begin{array}{lll}\text { Yes } & 404 & (76.9) \\ \text { No } & 119 & (22.7) \\ \text { Total } & 523 & (99.6) \\ \text { Missing } & 2 & (0.4)\end{array}$

Does your hospital have an infection control unit?

$\begin{array}{lll}\text { Yes } & 320 & (61) \\ \text { No } & 109 & (20.7) \\ \text { Do not know } & 89 & (17) \\ \text { Total } & 518 & (98.7) \\ \text { Missing } & 7 & (1.3)\end{array}$

If yes, out of $100 \%$ how do you rate their activity?

\begin{tabular}{lll} 
Very low $(\leq 25 \%)$ & 29 & $(5.5)$ \\
Low $(26 \%-50 \%)$ & 98 & $(18.7)$ \\
Good $(51 \%-75 \%)$ & 80 & $(15.2)$ \\
Very good $(76 \%-100 \%)$ & 68 & $(13)$ \\
Total & 275 & $(52.4)$ \\
Missing & 250 & $(47.6)$ \\
\hline
\end{tabular}


Table 5 :Distribution of nurses' perception of safety and vaccinations to nosocomial infections

\begin{tabular}{llc}
\hline Variable groups & Frequency & Percentage \\
Have you taken any vaccine to protect you against nosocomial infections in the hospital? \\
\hline Yes & 330 & $(62.9)$ \\
No & 185 & $(35.2)$ \\
Total & 515 & $(98.1)$ \\
Missing & 10 & $(1.9)$ \\
& & \\
If yes, for what disease or infection? & & \\
& & \\
Tetanus (TT) & 24 & $(9.3)$ \\
Tuberculosis (TB) & 3 & $(1.2)$ \\
Influenza & 33 & $(76.7)$ \\
Hepatitis B virus (HBV) & 198 & \\
Not mentioned & 72 &
\end{tabular}

How do you rate the safety of your workplace for nosocomial infections out of $100 \%$ ?

$\begin{array}{lll}\text { Very low }(\geq 25 \%) & 64 & (12.2) \\ \text { Low }(26 \%-50 \%) & 145 & (27.6) \\ \text { Good }(51 \%-75 \%) & 110 & (21) \\ \text { Very good }(76 \%-100 \%) & 127 & (24.2) \\ \text { Total } & 446 & (85) \\ \text { Missing } & 79 & (15)\end{array}$

Are you afraid to get an infection in the hospital?

$\begin{array}{lll}\text { Yes } & 427 & (81.3) \\ \text { No } & 85 & (16.2) \\ \text { Total } & 512 & (97.5) \\ \text { Missing } & 13 & (2.5)\end{array}$

How do you rate your compliance with hygiene rules during your procedures on patients?

$\begin{array}{lll}\text { Very low }(\geq 25 \%) & 4 & (0.8) \\ \text { Low }(26 \%-50 \%) & 34 & (6.5) \\ \text { Good }(51 \%-75 \%) & 87 & (16.5) \\ \text { Very good }(76 \%-100 \%) & 347 & (66.1) \\ \text { Total } & 472 & (89.9) \\ \text { Missing } & 53 & (10.1)\end{array}$

How seriously do you take nosocomial infections?

\begin{tabular}{lll} 
Very serious & 397 & $(75.6)$ \\
Not seriously & 45 & $(8.6)$ \\
Not care & 10 & $(1.9)$ \\
Not sure & 57 & $(10.9)$ \\
Total & 509 & $(97)$ \\
Missing & 16 & $(3)$ \\
\hline
\end{tabular}


Nurses' suggestions to the hospitals regarding the control of nosocomial infections. Most nurses (110) suggested establishing a more effective infection control unit as the best way for their hospital to be more effective against NIs (48.2\%), followed by continuing training to staff suggested by 54 nurses $(23.7 \%)$, care more about hospital hygiene by 24 nurses (10.5\%), better hospital building by 17 nurses $(7.5 \%)$, better administration to hospital by 13 nurses (5.7\%) and provide more PPEs by 10 nurses (4.4\%) (Figure 4).

\section{To be hospital more effective against nosocomial infection what do you suggest?}
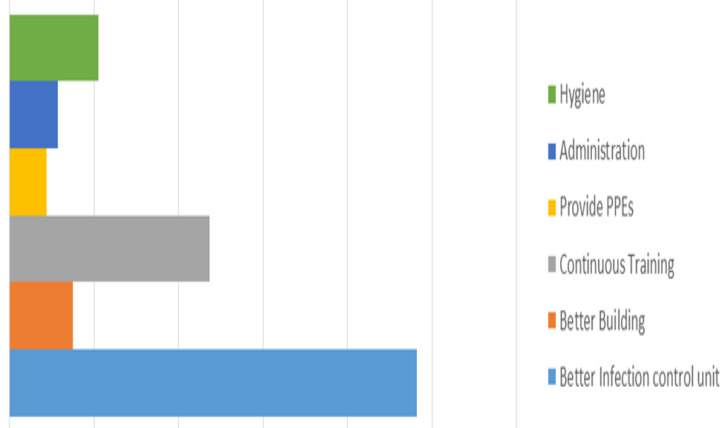

Figure 4 Nurses' suggestions to the hospital regarding control of nosocomial infections

\section{DISCUSSION}

This cross-sectional study evaluated nurses' self-report on the infection control unit activities and their experiences toward nosocomial infections in 10 Sulaimani governmental hospitals from 20 February to 28 September 2018 with the convenience sampling of 525 nurses using a questionnaire for data collection. In developing countries, the main obstacle to infection control units is the lack of or insufficient basic personal protective equipment for all staff [4]. In this study, the majority of nurses reported that the hospital provides vides sufficient uniforms for all nurses. Oliveira's review on nine articles from 2000 to 2010 shows that medical staff uniforms and gloves are among the main sources of microorganisms, including the resistant microorganisms [22]. The white coat used by some medical staff and students for hospital work practices is known as a source of potential microorganisms $[23,24]$. Hospital staff clothes acquire NIs during different procedures and through various contacts in the hospital environment and can transmit the infection from one patient to another. Wiener recommends that health staff should wear daily washed uniforms, cleaned through adequate laundry by a specialist hospital team under the supervision of the infection control unit [25]. The infection control unit is responsible for the application and monitoring of all infection control guidelines to prevent NIs [26]. Unorganized and ineffective infection control unit is one of the main causes of NIs in developing countries compared to developed countries [3]. In the current study, $84.6 \%$ of nurses reported that they wash their uniform themselves, and $55.6 \%$ of nurses reported there is no special team at the hospital to check and monitor uniform hygiene. The majority of nurses in this study reported that they did not experience an accident in the hospital that may cause them NIs, the needlestick injury was the highest accident among those nurses who experienced accidents, followed by cutting by sharp objectives. Alazawy's study on the prevalence of needle-stick accidents and knowledge on standard precaution and blood-borne diseases among medical staff reported that $53 \%$ of nurses in his study experienced a needle-stick injury [27], and Honda reported that $55.5 \%$ of nurses experienced sharp injuries accident, $91.1 \%$ of accidents involved blood, and the most common injuries were a needle-stick injury (52.8\%) 
followed by cutting by ampule (26.2\%). The majority of nurses in the current study were aware of the fact that their hospital has an infection control unit and the majority of them gave a low rating to the unit's role in the hospital. All the hospitals included in the current study have an infection control unit with low activity as nurses reported. Non-organized or non-active infection control units remain one of the main obstacles in developing countries against good control and prevention of NIs. The infection control unit is responsible for all applications and monitoring of standard and special precautions in each hospital including improving nurses' knowledge by training. Infection control units should be working more actively, to be provided with more guidelines and to be stricter in implementing the guidelines. More than half of the nurses who participated in this study were vaccinated against NIs, and HBV was the most common diseases nurses were vaccinated against. These results are in agreement with Eskander's study that showed that $80 \%$ of nurses received a vaccine against NIs, $74 \%$ of those vaccines were for HBV and $11 \%$ for the influenza virus. Fashafsheh reported that more than $80 \%$ of nurses who participated in their study were vaccinated against HBV [28].The majority of nurses in the current study gave a low rating to the safety in their hospital. Low perception of safety during their work in hospital decreases nurses performance and can cause injuries to themselves and the patients [29]. Also, the majority of nurses in this study were afraid of occupational NIs during their work in the hospital, they took NIs very seriously, and gave a high rating to their compliance to hygiene during procedures on patients. Nurses' fear of occupational NIs might make nurses more compliant and more careful about infection control precautions when dealing with patients and working in the hospital environment.

\section{CONCLUSION}

The majority of nurses reported that their hospital provided uniforms, which they washed themselves, and there was no dedicated team for checking and cleaning health staff uniforms. Most of the participating nurses were vaccinated against one or more nosocomial diseases, mostly against Hepatitis $B$. In addition, the majority of nurses did not feel safe in hospitals and were afraid to acquire nosocomial infections. Most nurses recommended the establishment of more effective infection control units that can be more active against nosocomial infections.

\section{REFERENCES}

[1] Obiero CW, Seale AC, Berkley JA. Empiric treatment of neonatal sepsis in developing countries. The Pediatric infectious disease journal. 2015;34(6):659-61. DOI:10.1097/ INF.0000000000000692.

[2] Nejad SB, Allegranzi B, Syed SB, Ellis B, Pittet $D$. Health-care-associated infection in Africa: a systematic review. Bulletin of the World Health Organization. 2011;89:757-65. DOI:10.2471/BLT.11.088179.

[3] Samuel S, Kayode O, Musa O, Nwigwe G, Aboderin A, Salami T, et al. Nosocomial infections and the challenges of control in developing countries. African journal of clinical and experimental microbiology. 2010;11(2). DOI:10.4314/ajcem.v11i2.53916.

[4] Alp E, Leblebicioglu H, Doganay M, Voss A. Infection control practice in countries with limited resources. Annals of Clinical Microbiology and Antimicrobials. 2011;10(1):36. DOI:https://doi.org/10.1186/1476-0711-1036.

[5] Engemann JJ, Friedman JY, Reed SD, Griffiths RI, Szczech LA, Kaye KS, et al. Clinical outcomes and costs due to Staphylococcus aureus bacteremia among patients receiving long-term hemodialysis. Infection Control and Hospital Epidemiology. 2005;26(6):5349. DOI:https://doi.org/10.1086/502580. 
[6] Kaye KS, Anderson DJ, Sloane R, Chen LF, Choi Y, Link K, et al. The effect of surgical site infection on older operative patients. Journal of the American Geriatrics Society. 2009;57 (1):46-54. DOI:https://doi.org/10.1111/ j.1532-5415.2008.02053.x

[7] Scott RD. The direct medical costs of healthcare-associated infections in US hospitals and the benefits of prevention. 2009.

[8] Glance LG, Stone PW, Mukamel DB, Dick AW. Increases in mortality, length of stay, and cost associated with hospital-acquired infections in trauma patients. Archives of Surgery. 2011;146(7):794-801.DOI:10.1001/ archsurg.2011.41.

[9] Lepelletier D, Perron S, Bizouarn P, Caillon J, Drugeon $\mathrm{H}$, Michaud J-L, et al. Surgical-site infection after cardiac surgery: incidence, microbiology, and risk factors. Infection Control and Hospital Epidemiology. 2005;26 (5):466-72.DOI:https:// doi.org/10.1086/502569.

[10] WHO. The burden of healthcare-associated infection worldwide 2016 [Available at: http://www.who.int/gpsc/country_work/ burden_hcai/en/.

[11] McBryde E, Bradley L, Whitby M, McElwain D. An investigation of contact transmission of methicillin-resistant Staphylococcus aureus. Journal of Hospital Infection. 2004;58 (2):104-8.DOI:https://doi.org/10.1016/ j.jhin.2004.06.010.

[12] Shinde MB, Mohite VR. A study to assess knowledge, attitude and practices of five moments of hand hygiene among nursing staff and students at a tertiary care hospital at Karad. International Journal of Science and Research (IJSR). 2014;3(2):311-21.

[13] de Oliveira AM, White KL, Leschinsky DP, Beecham BD, Vogt TM, Moolenaar RL, et al. An outbreak of hepatitis $C$ virus infections among outpatients at a hematology/ oncology clinic. Annals of Internal Medicine. 2005;142(11):898-902.

[14] Pessoa-Silva CL, Hugonnet S, Pfister R, Touveneau S, Dharan S, Posfay-Barbe $K$, et al. Reduction of healthcare-associated infection risk in neonates by successful hand hygiene promotion. Pediatrics. 2007;120(2):e382e90. DOI:https://doi.org/10.1542/peds.20063712.
[15] Joshi R, Reingold AL, Menzies D, Pai M. Tuberculosis among health-care workers in low -and middle-income countries: a systematic review. PLOS Medicine. 2006;3(12):e494. DOI:10.1371/journal.pmed.0030494.

[16] Kelcíkova S, Skodova Z, Straka S. Effectiveness of hand hygiene education in a basic nursing school curricula. Public Health Nursing. 2012;29(2):152-9. DOI:https:// doi.org/10.1111/j.1525-1446.2011.00985.x

[17] Damani N. Manual of infection prevention and control: OUP Oxford; 2011.

[18] Saleh Moghadam R, Mir Salari N. Knowledge and practice of nurses in relation to operating room pollution. Journal of knowledge management. 2005;39:21-8.

[19] Stone PW, Hasan S, Quiros D, Larson EL. Effect of guideline implementation on costs of hand hygiene. Nursing economic. 2007;25 (5):279.

[20] Daniel W. Biostatistics: A Foundation for Analysis in the Health Sciences, 7th ed $\mathrm{R}$ Wiley. New York. 1999.

[21] Kaushal G, Doke P, Shah A, Verma V. An analysis of knowledge, attitude and practices regarding standard precautions of infection control and impact of knowledge and attitude of ICU nurses on self-reported practices of infection control. International Journal of Hospital and Health care Administration. 2015;2:79-85.

[22] Oliveira ACD, Silva MDM, Garbaccio JL. Clothing of health care professional as potential reservoirs of micro-organisms: an integrative review. Texto \& ContextoEnfermagem.2012;21(3):684-91. DOI:https://doi.org/10.1590/S010407072012000300025

[23] Robati R, Farokhi MM, Jaberi FM, Hashemi SA. Effect of white coats on spread of nosocomial infection. European Journal of Experimental Biology. 2013;3(3):156-9.

[24] Banu A, Anand M, Nagi N. White coats as a vehicle for bacterial dissemination. Journal of clinical and diagnostic research: JCDR. 2012;6(8):1381.DOI:10.7860/ JCDR/2012/4286.2364

[25] Wiener-Well Y, Galuty M, Rudensky B, Schlesinger $Y$, Attias D, Yinnon AM. Nursing and physician attire as possible source of nosocomial infections. American Journal of Infection Control. 2011;39(7):555-9. 
[26] Storr J, Twyman A, Zingg W, Damani N, Kilpatrick C, Reilly J, et al. Core components for effective infection prevention and control programmes: new WHO evidence-based recommendations. Antimicrobial Resistance \& Infection Control. 2017;6(1):6. DOI:https:// doi.org/10.1186/s13756-016-0149-9

[27] Alazawy SA. The Prevalence of Needle Stick Injuries among Health Care Workers in Baquba Teaching Hospital. Diyala Journal For Pure Science. 2010;6(3):260-71.

[28] Fashafsheh I, Ayed A, Eqtait F, Harazneh L. Knowledge and Practice of Nursing Staff towards Infection Control Measures in the Palestinian Hospitals. Journal of Education and Practice. 2015;6(4):79-90.

[29] Barton A. Patient safety and quality: An evidence-based handbook for nurses. AORN Journal. 2009;90(4):601-2. DOl:https:// doi.org/10.1016/j.aorn.2009.09.014 